\title{
The Polycentricity of Climate Policy Blockage
}

\author{
Dana R. Fisher ${ }^{1}$ and Philip Leifeld ${ }^{2}$
}

${ }^{1}$ Department of Sociology, University of Maryland, 2112 Parren Mitchell Art-Sociology Building, 3834 Campus Drive, College Park, MD 20742.

${ }^{2}$ Department of Government, University of Essex

* Corresponding author: $\underline{\text { drfisher@umd.edu }}$

\section{Acknowledgements:}

This research was supported by the MacArthur Foundation (\#G-1604-150842 and \# G-16-1609151514-CLS). The funding source had no involvement in research design, data collection, analysis, or interpretation of these findings.

This paper benefited from input from participants at the International Studies Association and the European Workshops in International Studies meetings in 2017, as well as an INOGOV EU COST Action workshop on polycentricity and legitimacy in 2016.

The authors would like to thank Amanda Dewey, Ann H. Dubin, Anya Galli Robertson, Joseph McCartney Waggle, and William Yagatich for their research assistance. 


\title{
The Polycentricity of Climate Policy Blockage
}

\begin{abstract}
:
This paper builds on recent research on polycentric governance and the Ecology of Games to understand climate politics in the United States. Complementing previous work from 2005-2009, we map out the ideological networks of political actors engaged in the climate policy network using data from the US Congress as an arena of symbolic interactions. Our analysis identifies polycentric sites of ideological congruence and conflict in the discourse network on climate change. Political actors from different levels and including several actor types formed multiple centers that became bipolarized between the 112th and 114th Session of the US Congress. This process took place in tandem with the increased participation of subnational actors in the polycentric system. By the 114th Session of Congress_-during which the 2016 election took place-subnational policy actors, along with a diversity of other actors, contributed to an extremely polarized discussion of one of the central policies in the Obama Administration's Climate Action Plan: the Clean Power Plan. This finding is remarkable as the concept of polycentricity is usually normatively associated with policy innovation, rather than stagnation. Our longitudinal analysis demonstrates, using Discourse Network Analysis, how increased multi-level participation can be associated with policy blockage of progressive climate policies rather than enabling policy innovation.
\end{abstract}

\section{Declarations of Interest: None.}




\section{Introduction}

Before the 2016 U.S. presidential election, which brought a climate skeptic into the White House, numerous studies had pointed to emergent subnational opportunities to fill what had been called a climate "policy void" at the federal level (Krane 2007:462; see also Jones 1991; Rabe 2007; Fisher 2013). When a policy void exists, the literature on polycentric governance (Ostrom 2014:121, see also 2012; Cole 2011) would advise us that actors from multiple scales and levels in different subsystems step up in order to produce policy innovation (Jordan et al. 2015, 2018). This research

tends to promote "the normative prescription that polycentric systems are more effective" (Berardo and Lubell 2019:7) and describes scenarios in which collective action dilemmas are overcome through the involvement of actors at different "centers" of a political system (Ostrom 2012, 2014).

Instead of innovating, however, this policy void in the U.S. was filled by subnational actors seeking to block progressive climate policy. In this contribution, employ the methodology of Discourse Network Analysis to illustrate how polycentric governance sometimes produce adverse outcomes. Specifically, we look at how actors from different levels get involved when the centers of a polycentric system are characterized by ideological conflict. In making this argument, we draw on the adjacent literatures of polycentric governance, the Ecology of Games, and network science.

\section{Polycentric Governance, Discourse Networks, and Policy Blockage}

Environmental politics are characterized by the involvement of multiple actors at different levels and in different parts of a political system (McGee and Jones 2019). In fact, network analysis has been applied numerous times to study the structure of the actor network in U.S. climate politics (e.g. Jasny, Waggle, and Fisher 2015). Here, we extend this line of research and update earlier analyses (Fisher, Leifeld, and Iwaki 2013; Fisher, Waggle, and Leifeld 2013) using the same methodology and 
more recent data from 2011 to 2016 in order to show how this complex actor network was engaged in climate policy blockage primarily from subnational actors.

The complexity of the actor network has often been characterized using the concept of polycentric governance. In recent years, much of this research has focused on global climate politics and the Paris Agreement, which was signed in 2015 (see particularly Cole 2015; Gillard et al. 2017; Jordan et al. 2018; Morrison 2017; Oberthür 2016; Ostrom 2012; Spreng, Sovacool, and Spreng 2016). Polycentricity describes a situation in which multiple actors from different parts of a system interact to produce decentralized outcomes (Carlisle and Gruby 2017). Such a decentralized structure is regarded as beneficial because it overcomes the stalemate often incurred by hierarchical forms of organization (Jordan et al. 2018; Oberthür 2016), as well as collective action problems resulting in policy gridlock (Berardo and Lubell 2019; see also Lubell, Henry, and McCoy 2010). In short, decentralized forms of bargaining, developing shared understandings, and developing and implementing solutions with an involvement of actors at different levels and places in the respective political system are often viewed as a way to produce policy innovation (Carlisle and Gruby 2017; see also Cole 2015). Building on the influential work of Ostrom and her colleagues, this approach finds that "multiple benefits are created by diverse actions at multiple scales" (Ostrom 2014:121, see also 2012; Cole 2011). In other words, this research encourages the multi-level governance of climate change (for a full discussion, see Betsill and Bulkeley 2006).

Studies view this shift to involve an evolution from formal, command-and-control government procedures and debates over deregulation to instances of collaborative governance of natural resources that reveal a complex web of state and non-state actors interacting at multiple scales (Cole 2015; Koontz et al. 2004; Oberthür 2016; see also Bodin 2017). Perhaps Oberthür best summarizes this perspective in his paper on the polycentricity of the climate regime after the Paris round of the climate negotiations (COP-21) in 2015. "A wealth of governance levels (local, regional, 
national supranational, international), public and private actors and fora have become recognised as driving forces of climate action in their own right" (Oberthür 2016:10)

This research highlights how sub-national and local environmental organizations are working among a much broader set of partners and exchange of ideas. Focusing in particular on the subnational level, research has assessed how, in light of the delayed response by national governments to global environmental issues such as climate change, many cities have implemented their own environmental protection programs. Rabe calls these efforts "races to the top" (Rabe 2013; Rabe and Borick 2013; see also Betsill and Bulkeley 2006; Bulkeley 2005).

It is clear from this exposition that polycentric arrangements can be analyzed using tools from network science, which focus explicitly on the connections between different centers of a system, as well as their internal organization. The literature on polycentric governance from an Ecology of Games perspective has contributed to this line of research by focusing on the connections of localized actors through shared policy forums as an emergent complex social system (Berardo and Lubell 2019; García and Bodin 2019; Scott and Greer 2019; see also Lubell et al. 2010; Hamilton and Lubell 2018). A policy forum is an organization that connects a range of stakeholders and facilitates a multipartite exchange between the participating parties in order to produce decentralized policy solutions (Fischer and Leifeld 2015). The web of overlapping memberships in these forums shapes an evolving network with multiple centers, or clusters, in which power is exercised, outcomes are negotiated, and shared meaning is developed.

However, in the Ecology of Games perspective on polycentric systems, the actual processes taking place at these different centers of the network largely remain a black box and can vary to a great extent across parts of the system (Fischer and Leifeld 2015). Carlisle and Gruby (2017) assert that while autonomy is a necessary precondition for different centers in a polycentric system, there are certain mechanisms that can be distinguished in the interplay of the different parts of a 
polycentric governance system. From a network and complexity perspective, such complex, emergent outcomes are the consequence of interactions among different parts of a system. For a system to be characterized as a polycentric governance system, the mechanisms of competition, cooperation, conflict, and conflict resolution between the different centers need to be disentangled (Carlisle and Gruby 2017). At the same time, whether or not positive outcomes, or innovations, are produced by the system collectively or whether adverse outcomes, or blockage, are generated depends on the interplay of these different centers and is largely an empirical question. Answering this question, Berardo and Lubell have identified the need for analysis of longitudinal data regarding how polycentric systems develop over time.

We aim to contribute to this literature by focusing on the ways actors in U.S. climate politics link to each other and form centers that span multiple levels. Specifically, we look at the involvement of subnational actors and their contribution to amplifying policy conflict between different centers of the complex system while inducing a larger policy congruence within their respective centers. As there are no institutional mechanisms for conflict resolution in place across the different parts of the system, the result was policy gridlock, which contributed to the eventual termination of a central policy initiative, the Clean Power Plan.

However, we propose to focus on an aspect of polycentric governance that has been neglected in favor of analyzing the overall structure of the complex network. Our contribution is to analyze the congruence and conflict among actors and the centers they form over time at the ideological, or symbolic, level. This approach enables us to map the sources of cooperation and conflict and how they lead to a polarized topology of the polycentric network over time. We specifically study the discourse network around climate change to understand the shared policy beliefs of actors, how they lead from multiple centers to polarized camps over time, and what role 
subnational actors played in this process. Our analysis speaks directly to several claims made in the literature on polycentric governance:

First, we address Lubell and Berardo's (2019) claim that such systems need to be analyzed empirically, with the full force of network analysis and complexity science, to find out how they are structured and what they actually produce: innovation or blockage - rather than taking a positive outcome for granted, as the majority of work on polycentricity seems to imply (Lubell and Berardo 2019). Indeed, we illustrate this point using a case where the involvement of actors from a different level is associated with adverse outcomes.

Proposition 1: The involvement of actors from a different level can lead to adverse outcomes (policy blockage), rather than innovation, in a polycentric governance system.

Second, we address the same authors' claim that little empirical work has been done in a longitudinal fashion to evaluate how polycentric politics play out over time and how key actors can change the structure and hence overall outcomes of a system. To this end, we extend earlier analyses on the $109^{\text {th }}$ and $110^{\text {th }}$ Sessions of the U.S. Congress using the same methodology (Fisher, Leifeld and Iwaki 2013) by three additional time periods, the $112^{\text {th }}, 113^{\text {th }}$, and $114^{\text {th }}$ U.S. Congress, to understand how the new involvement of a set of subnational actors contributes to polycentricity and policy outcomes.

Proposition 2: Only a longitudinal empirical perspective can document the changes in a polycentric governance system that lead to policy outcomes.

Third, we operationalize some of the different mechanisms outlined by Carlisle and Gruby (2017) in their theoretical work on polycentric governance: we measure conflict and congruence between actors and their centers through a content analysis of their policy beliefs. This operationalization enables us to map cross-sectionally and over time what the different centers are in terms of their overlapping policy beliefs, who their members are, how they relate to each other ideologically, and how their evolution led to climate policy blockage by the end of the period under 
study. The analysis demonstrates how there is actually a "structural hole" (Burt 1995) between centers in terms of policy belief congruence, which only widens with the increased participation of subnational actors on each side of the increasingly bipolar and less multipolar network.

Proposition 3: Ideological congruence and conflict in discourse networks structure the (polycentric or bipolar) topology of a governance network, and this topology may be altered by cross-level involvement of new actors.

This effort is a clear departure from the Ecology of Games perspective, which deals with the structure, rather than the contents, of the network. The Ecology of Games perspective provides insights into the generation of shared meaning through forums, but also into negotiations and multipartite exchange (Lubell, Henry, and McCoy 2010; Fischer and Leifeld 2015), but it does not unpack this black box. Our contribution, in contrast, provides a complementary perspective by focusing exclusively on the generation of shared meaning through policy belief congruence or conflict at the expense of the other types of exchange in policy forums. In other words, it opens the black box and uses actual belief relations to operationalize centers in a governance system. The following analysis also focuses on a relatively specific, but important, arena of governance: the network of actors who are active on the national stage through their testimony in the U.S. Congress.

\section{Congressional Hearings as an Arena for Polycentric Governance}

Congressional testimonies provide direct accounts of the discourse and debate around climate policymaking, as well as the issue more broadly. We build on the earlier studies by McCright and Dunlap (2003), Liu and colleagues (2011), as well as previous work by Fisher and colleagues (2013a, 2013b), all of which analyze Congressional hearings to understand climate politics in the US. Congressional hearings are an important part of the policymaking process in the United States. In the words of the United States Governmental Printing Office, Congressional hearings are the principal way that members of Congress "obtain information and opinions on proposed legislation, 
conduct an investigation, or evaluate/oversee the activities of a government department or the implementation of a Federal law."1 The importance of such hearings as a source of information has been noted within the academic literature as well (see particularly Clifton 2004; Gormley Jr 1998).

An array of experts give testimony at Congressional hearings, including governmental agency officials, interest groups, businesses, think tanks, and academic researchers, as well as members of the US Congress themselves (for a more general discussion of congressional hearings, see Burstein and Hirsh 2007; DeGregorio 1998). Congressional hearings provide a forum for different policy actors to achieve recognition for their interests and perspectives, and to garner the attention and support of different political constituencies. Testimonies are intended to inform decisionmakers about a range of topics germane to the policy issue at hand. According to Burstein and Hirsh, "members of Congress believe that hearings provide an efficient way to gather information and exert influence. [...] Interest organizations, too, see hearings as important venues for conveying information” (Burstein and Hirsh 2007:179; see also Laumann and Knoke 1987).

Congressional hearings, then, represent a field site wherein one can study how science, politics, and economic interests collide in ways that influence climate change policy, or the notable lack thereof. Even though the rules of both houses of the US Congress stipulate that the minority party is given the opportunity to call witnesses at Congressional hearings, participation in hearings varies based on what party has the majority in Congress. In the words of a report by the Congressional Research Service regarding the Senate practice, "typically, the members of a committee from each party work together informally to invite witnesses representing various views" (Heitshusen 2017:1; see Congressional Research Service 2015 on the House).

The asymmetries that result from participation based on the majority rule, have been found also to have implications to the content of Congressional Hearings. Park and colleagues, for

${ }^{1}$ https://www.govinfo.gov/help/chrg (Accessed 9 May 2019) 
example, note that hearings on climate change are more likely to take place during a Democratcontrolled Congressional session and such hearings tend to feature testimony from more proenvironment political actors and mainstream scientists (Park, Liu, and Vedlitz 2010). During Republican-controlled Congressional sessions, testimonies are more likely to focus on the negative implications of regulating carbon dioxide (2010). In a more recent analysis, Fisher and colleagues find less polarization around the issue of climate change during the 110th Session of Congress, when the Democrats held the majority in the House of Representatives and the voting share in the Senate (Fisher, Leifeld, et al. 2013). Even with these noted challenges, the perspectives presented during Congressional hearings provide a good data source for understanding the polycentric network engaged in this contentious issue.

Building on the literature presented and the three propositions generated from it, this paper analyzes the content of Congressional hearings on climate change policy. In so doing, we focus, not just on who has a say in the climate change debate in Congress, but what they are saying, and with whom they are aligning. Our dataset includes all testimonies from hearings related to the issue of climate change during the $112^{\text {th }}, 113^{\text {th }}$, and $114^{\text {th }}$ sessions of the US Congress (for a full discussion of the dataset, how it was assembled, and how data were analyzed, see methods supplement). The $112^{\text {th }}$ (January 5, 2011-January 3, 2013) took place during the second half of President Obama's first term. The $113^{\text {th }}$ Congress and $114^{\text {th }}$ Congress (January 3, 2013-January 3, 2015 and January 6, 2015January 3 , 2017) span the entirety of the second term of the Obama Presidency. During the $112^{\text {th }}$ and $113^{\text {th }}$ sessions, there was a Democratic majority in the Senate and a Republican majority in the House of Representatives. During the $114^{\text {th }}$ Congress, there was a Republican majority in both Houses of the Congress.

These three sessions of Congress are particularly notable as they directly followed the failure of the cap-and-trade bill in the $111^{\text {th }}$ Session of Congress(for discussion, see Jasny et al. 2015) . 
Moreover, it was during these sessions of Congress that President Obama's Clean Power Plan was released and debated. President Obama formally announced the Clean Power Plan (CPP) in 2015, ${ }^{2}$ calling the proposed regulation "the single most important step America has ever taken in the fight against global climate change" (Obama 2015). The policy aimed to reduce carbon dioxide emissions from power plants through an Executive Order that would be enforced by the EPA and implemented through various means on a state-by-state basis. By adopting the domestic emissions reduction goals included in the CPP (32 percent within 25 years relative to 2005 levels), the Obama Administration was able to participate in the international climate negotiations in Paris at COP-21 with the knowledge that it could follow through on its international commitments (for more details, see The New York Times 2017).

Political opposition to the CPP was quickly apparent. In some cases, states had, independent of the policy, already implemented plans for reducing emissions. Progress made by these states previous to the expected start date of the CPP was not expected to be counted toward their mandated goals. Mere days after President Obama announced the Plan, governors and attorneys general from 27 states signed a letter announcing their intention to oppose it on the grounds that it was federal overreach into state affairs (Harvard Law Review 2016). In February 2016, during the second half of the $114^{\text {th }}$ Session of the Congress, the US Supreme Court stayed implementation of the Plan until the legal challenges to the program could be concluded (Harris 2016). The stay remained in effect until the Trump Administration replaced the policy after taking office.

\footnotetext{
2 The Clean Power Plan was first proposed by the Obama Administration in June 2014. For details, see https://19january2017snapshot.epa.gov/cleanpowerplan/clean-power-plan-existing-power-plants .html\#rule-history (accessed 8 May 2019).
} 


\section{Data and Methods}

\section{Content Coding}

We employ the methodology of previous studies to create a dataset from hearings during these three sessions of the US Congress (Fisher, Leifeld and Iwaki 2013; Fisher, Waggle and Leifeld 2013; for details, see methods supplement). Consistent with this previous work on the subject, the testimonies were coded for ten concepts that are particularly relevant to discussions about climate change policy in the United States. Coding involved noting whether the speaker agreed or disagreed with the specific concept.

Two of the concepts were about the science of climate change, which has been a central theme in the climate change debate in the United States for many years: "climate change is real and anthropogenic" and "climate change is caused by greenhouse gases." The eight other concepts were about different climate policy issues/instruments: "legislation should regulate carbon dioxide emissions," "legislation that regulates carbon dioxide emissions will not hurt the economy," "legislation should establish a market for carbon emissions (cap and trade)," "legislation should establish a carbon tax," "the Federal government (not states) should take the lead on climate policy," "Climate change (or failing to address climate change) poses a security threat," "States should accept the Clean Power Plan," and "The US should meet or exceed the 26\%-28\% emissions reduction target by 2025 against a 2005 baseline (per the Paris agreement)." With these concepts, we focus on what Sabatier and Weible call 'policy core beliefs' as they are preferences regarding the key dimensions of a specific policy or the 'glue that binds coalitions together' (2007). Whenever a statement falling under one of the ten concepts was made, the statement was coded as either agree or disagree. In some cases, statements included mention of both sides of the issue, suggesting that the speaker holds a moderate or ambivalent stance on the issue. In these cases, the speaker was coded as both agreeing and disagreeing. The software Discourse Network. Analyzer (Leifeld 2016) and 
the $r D N A$ R package (Leifeld 2019) were used to code the actor-concept statements and analyze the resulting networks.

\section{Network Analysis Technique}

The methodology and data collection are consistent with the procedures outlined in Fisher et al. (2013) and are summarized in our methods supplement. A "statement" is a text portion where an actor reveals his or her policy beliefs or preferences in the text (Leifeld 2019; Leifeld and Haunss 2012). All statements were transformed into an actor-by-concept matrix where each category occupies two distinct columns - one for positive statements, indicating the actor supports the claim, and one for negative statements, when the actor opposes it (i.e., reflecting agreement and disagreement with each concept). In network terminology, it can be understood as an affiliation matrix (also known as two-mode network or bipartite graph) with two classes of nodes: actors and concepts. To avoid confounding the quantity of an actor's statements and the actor's qualitative preferences, we dichotomized the affiliation matrix in some of the procedures that follow, retaining “ 0 " values where present and replacing positive values by the value "1" (i.e., ignoring duplicate statements). In the multivariate network procedures described below, this process guarantees that actors are modeled as showing a high degree of belief similarity if they judge many different concepts in the same way, not if they agree on a single concept repeatedly during Congressional Hearings.

A full array of network-analytic methods can be used to analyze the ideological network. In our analysis, we employ network modularity (Newman 2006) and a cluster analysis to describe the network structure. We embed these into a qualitative interpretation of the network diagrams and the political process. More specifically, the data were analyzed in the following four related ways, with identical analyses for the three different sessions. 
First, we conducted an agglomerative hierarchical cluster analysis (Jain and Dubes 1988) with Ward's optimization (Ward 1963). This analysis serves to identify the community structure of the actors based on their stated policy beliefs. We employed the Jaccard coefficient to create a distance matrix from the actor-concept matrix. The resulting distance matrix was clustered in order to find subgroups of actors who held similar beliefs. The Jaccard coefficient is known to have normalizing properties in the sense that the number of statements made, or the number of beliefs held, does not affect the similarity to other actors. This procedure was chosen over three other nested clustering techniques based on the Jaccard distances and over four community detection techniques based on one-mode network data using the criterion of network modularity in the positive-valued one-mode network (see below). The results are presented as dendrograms, where the height at which two actors or groups of actors are merged together represents their distance in the Jaccard distance matrix. If two actors were merged at a relatively low level, they held relatively similar, or congruent, policy beliefs (see also Leifeld 2016). The order of actors merged at the same agglomeration height is random. Cluster membership in the dendrograms is denoted by different symbols next to the leaves (circles versus rectangles for the different clusters), while the colors of the node labels represent the nine actor types. Clusters of nodes in this network represent different centers in the polycentric governance system, based on the assumption that centers can be measured in terms of their similarity of policy beliefs. The discourse network is a good overall indicator of the empirical existence of centers, their between-group conflict or polarization, and their within-group congruence in US climate politics. The interpretation in the Results section below uses the actor types represented by node label colors to describe the different centers in terms of their actor composition and analyze the involvement of subnational actors.

Second, we computed network modularity (Newman 2006) for each cluster solution in the positive-valued subtracted one-mode network (see below). In the cluster analysis, we chose two 
clusters per Session of Congress because this corresponded to the expected polarization known from earlier studies (Fisher et al. 2013). Network modularity also confirmed that a solution with two clusters exhibited a better goodness of fit than solutions with three or four clusters. Modularity is a measure of the extent to which a network is characterized by multiple subgroups, i.e., a measure of fragmentation of the network into centers, given a partition of nodes into centers as computed by the cluster analysis. Modularity is defined between -0.5 and 1.0. Networks with high modularity (practically above 0.4 ) are characterized by a strong division into separate centers, where there are dense connections between the nodes within a center and sparse connections across different clusters (see Newman 2006 for details).

Third, we visualized the actor-concept affiliation network as a signed bipartite graph, for each Session of Congress separately. In these networks, actors were represented by circles and concepts by rounded rectangles, and ties between an actor and a concept as lines, with positive referrals of a concept by an actor highlighted in green, negative referrals in red, and ambiguous relationships in blue. These visualizations show how the clusters in the dendrograms came about. With increasing complexity of the diagrams that have larger numbers of actors in later sessions, we decided to omit actor labels and types and highlight only the behavior of subnational actors in order to identify their role in the ideological networks and clusters more clearly.

Fourth, we converted the actor-concept affiliation networks into one-mode actor networks and visualized these networks as well, using the transformations described in earlier work (Leifeld 2016, 2017; Leifeld, Gruber, and Bossner 2018). We used the "subtract" method (Leifeld 2017) in the Discourse Network Analyzer software to express congruence between actors' use of concepts in excess of actors' conflicts over the ten concepts as follows: We first computed an actor congrence network. An actor congruence network contains only actors as nodes. The similarity between any two actors in terms of how many concepts they both referred to (i.e., both positively or both 
negatively) is represented by weighted ties between the actors. The tie weights were normalized by dividing them by their incident actors' average number of distinct concept referrals, in line with the previous work (see, in particular, Leifeld 2017). We then computed an actor conflict network, in which the tie weights between actors count how often they had different views on concepts (i.e., one actor referring positively to a concept and the other actor referring negatively to a concept). The conflict network was normalized in the same way as the congruence network, by dividing the tie weights by the average number of concepts the two actors involved in a tie referred to. Next, we subtracted the normalized conflict weights from the normalized congruence weights in order to create the one-mode network matrix in which positive ties indicate congruent actor beliefs in excess of conflict and in which negative ties indicate more conflict than congruence.

In the final step, we replaced all negative values by zero in order to retain only highcongruence ties between actors. This positive-valued subtracted network (Leifeld 2017) was used to compute modularity with a given cluster solution (see above). We also visualized the positive-valued subtracted network and highlighted clusters, or centers, of similar-minded actors using blue hyperplanes (as implemented in the graph drawing software visone). The community detection technique used for this purpose was the Louvain algorithm as a fast and reliable technique for weighted networks (Blondel et al. 2008) and as a complementary clustering technique to the hierarchical clustering outlined above. The visualizations with embedded cluster analysis show the polarization of the ideological network in each Session of Congress while retaining the actor labels. We interpreted the location and role of different actor types (indicated here by node color) and most notably subnational actors in the centers over time to assess their role in the polycentric governance system. 


\section{Findings}

On the pages that follow, we present the results of our analyses of Congressional hearings related to the issue of climate change in the $112^{\text {th }}-114^{\text {th }}$ Sessions of the US Congress to assess the degree to which our analyses support our three propositions. We start by looking at the diversity of policy actors participating in these Hearings by actor type. Then, we present dendrograms based on the cluster analysis of the affiliation networks along with the ideological maps of how political actors are tied together by common categories and stances and how positions in this network map are related to organizational affiliations of participants in these hearings, focusing on how they changed from the $112^{\text {th }}$ to $114^{\mathrm{h}}$ sessions of the US Congress. The interpretation will focus on the location of subnational actors with regard to what categories they co-support or co-reject and in which clusters they are located as a consequence of these choices. Finally, we present the one-mode actor networks for the same time periods to evaluate the resulting polarization and the subnational actors' role in the network more clearly.

\section{Overall Participation in Congressional Hearings on Climate Change}

Building off the work by Burstein and Hirsh (2007), Gormley (1998), McCright and Dunlap (2003), as well as our previous work (Fisher, Waggle and Leifeld 2013), we analyze the types of actors who made statements during the Congressional hearings in our sample. Table 1 presents these results. Contrary to previous findings that scientists played a limited role in Congressional hearings on climate change (Fisher et al. 2013), scientists played a variable role in these hearings (about 29\% in the $112^{\text {th, }} 15 \%$ in the $113^{\text {th }}$ Congress, and $7 \%$ in the $\left.114^{\text {th }}\right)$. Participation by scientists in the $112^{\text {th }}$ Session of Congress right after the failure of the bill is particularly high. The $112^{\text {th }}$ session of Congress is also unique in the low levels of governmental participation from Congresspeople (about $5 \%$ for Democrats and 4\% for Republicans). One likely interpretation of this finding is that, after 
the failure of the cap-and-trade bill, Congressional representatives were less involved in the issue since there was no policy mechanism under debate. As a result, scientists were called more frequently to speak in these Congressional Hearings.

The distribution of the speakers from the $113^{\text {th }}$ and $114^{\text {th }}$ sessions of Congress is more consistent with previous analyses of Congressional Hearings, in that the majority of the speakers came from different branches of the US government. Since the Obama Administration formally introduced the Clean Power Plan during the $113^{\text {th }}$ session of Congress and then finalized it during the $114^{\text {th }}$ session, it makes sense that participation in Congressional hearings would grow in general and among representatives of the US government more specifically.

Beyond the varying levels of discussion around the issue of climate change, one of the most noteworthy differences in this analysis is the emergence of subnational actors playing an increasing role in these Congressional Hearings. Although subnational participation in hearings in previous sessions of Congress was so low that it was included in the "Other" category (Fisher et al. 2013), about $10 \%$ of participants were subnational governmental representatives across these three Sessions of the US Congress $\left(7 \%\right.$ in the $112^{\text {th }}, 12 \%$ in the $113^{\text {th }}$, and $9 \%$ in the 114 h Session accordingly).

The diversity of participation by various types of actors is consistent with the work on polycentric governance. Moreover, the increase in subnational governmental participation and then its persistence over time suggests that, even in the US Congress, a polycentric approach is being taken to address climate change (Cole 2015; Ostrom 2012).

TABLE 1 ABOUT HERE 


\section{Analyzing the Content of the Hearings}

Next, we present the results of analysis of the content of the testimonies presented in Congressional Hearings. Here, policy actors are separated into clusters based on their similarity across the ten concepts that were identified as particularly relevant to climate politics in the US. These results are graphically depicted as a dendrogram.

Figure 1 presents the results of this analysis of the ten concepts together for the $112^{\text {th }}, 113^{\text {th }}$, and $114^{\text {th }}$ sessions of the US Congress. Speakers within the $112^{\text {th }}$ Congress separate out into two distinct "camps" in this analysis: one dominated by scientists, environmental groups, and representatives from the Obama administration, which is denoted by rectangles on the right of the diagram; and the other dominated by business groups and think tanks, which is denoted by circles on the left. Since the climate bill failed the previous session of the Congress, these findings show that two polarized camps exist on the issue, which is not a surprise. The modularity of the twocluster solution is 0.348 , which is notable but not extremely high. Especially the cluster involving science, environment, and government is composed of multiple sub-groups, or sub-centers. Subnational actors are notably absent in this Session of Congress.

\section{FIGURE 1 ABOUT HERE}

Turning to the $113^{\text {th }}$ Congress, the dendrogram also separates into two distinct clusters: actors denoted with rectangles on the left and circles on the right. All of the environmental groups, almost all of the representatives from the Obama Administration, and most scientists are in the cluster on the right (denoted by circles). All but one of the Republican Legislators in the debate and a number of businesses are in the cluster on the left (denoted by rectangles). This cluster includes the vast majority of the sub-national actors who participated in the $113^{\text {th }}$ session of the US Congress. This center includes representatives from four states who gave testimony to the US Congress during a hearing in September 2014 representing an opposition by states to the Clean Power Plan. The 
modularity of the subtracted actor network given this two-cluster solution is 0.416 , which marks an increase over the previous legislative period and indicates greater polarization with less clear-cut subcenters within the two factions than before.

The debate in the $114^{\text {th }}$ Session of Congress (where the Republicans held the majority of both houses) is still characterized by a bipolarization between the two camps, as expected. However, there are three notable differences. First, all of the Republicans and many businesses opposed to the Plan (denoted by circles on the left) is now of almost equal size as the Democrat, environmental, and science cluster (denoted by rectangles on the right). Second, the number of subnational actors has increased in absolute numbers (though not in relative shares; cf. Table 1). The number of subnational actors has grown in both camps, with fifteen subnational actors in the Republican cluster and six in the Democrat and environmental cluster. There continues to be a relative overrepresentation of subnational actors in the oppositional camp, as in the previous Session. Third, the two main clusters appear more congruent within and more divided across. This finding is confirmed by a high modularity value of 0.443 , which is the highest among the three legislative periods.

To provide a micro-level interpretation of the role of subnational actors in these clusters, Figure 2 shows the signed affiliation networks, from which actors' stances on the ten concepts can be inferred. Actors are denoted by circles while concepts, or policy beliefs, are shown as squares. Green ties indicate a positive stance by an actor on a concept; red ties indicate a negative stance, and blue ties indicate both.

In the $112^{\text {th }}$ Congress, the most controversial concept is "Climate legislation will not hurt the economy." The only subnational actor that is present in the debate in the $112^{\text {th }}$ Congress—-the Texas Attorney General—has a negative stance on this issue, meaning that he stated that climate legislation will hurt the economy. 


\section{FIGURE 2 ABOUT HERE}

In the $113^{\text {th }}$ Congress, most of the conflicts emerge around the categories "Climate legislation will not hurt the economy" (as before) and two categories specifically around the role of subnational actors: "The Federal government (not states) should take the lead on climate policy" and "States should accept the Clean Power Plan."

With increasing numbers of actors in the $113^{\text {th }}$ Congress, the affiliation network visualization becomes harder to read. Figure 3, while otherwise identical to Figure 2, therefore highlights the role of subnational actors. Figure 3 reveals that subnational actors are much more active in the $113^{\text {th }}$ Congress and that their main issue is the rejection of the Clean Power Plan in the $113^{\text {th }}$ Congress. In other words, subnational actors team up to reject the Clean Power Plan in this debate.

In the $114^{\text {th }}$ Congress (Figure 3, lower diagram), the two concepts that engage subnational actors continue to be the most controversial issues. It is evident that the majority of subnational actors take a clear negative stance on the two issues, and a number of these actors co-rejects both categories.

\section{FIGURE 3 ABOUT HERE}

\section{Analyzing the location of subnational actors in the "centers" of the debate}

Figure 4 presents a transformation of the affiliation networks shown in Figure3, where only actors and the excess congruence in terms of policy beliefs is shown (see methodology section for details). The tie strength (and line width) between two actors is proportional to the (normalized) number of policy beliefs the two actors both hold (i.e., counting both co-support and co-rejection, but not mixed stances) in excess of conflicts between the same two actors. Hence, this form of visualization operationalizes the different relations theorized by, for example, Carlisle and Gruby (2017) and 
shows us where there is more congruence (a cooperative relation) than conflict between centers and sub-centers in the polycentric system.

\section{FIGURE 4 ABOUT HERE}

As in the dendrograms in Figure 1, one can see the two camps emerging in the debate, denoted by the blue hyperplanes, which show the result of a Louvain graph clustering procedure. With increasing time from the $112^{\text {th }}$ to the $114^{\text {th }}$ Session, the polycentric structure increasingly moves toward a clearly polarized two-center structure, which is in line with the modularity scores reported above. Only those actors who refer to three or more concepts are labeled in these figures. Node size corresponds to the number of relevant statements made by the respective actor.

In this figure, it is easy to see how many of the subnational actors cluster together in the $113^{\text {th }}$ Congress and are adjacent to business actors and mostly Republicans (but also to some Democrats), which is mostly due to their stances on the Clean Power Plan (see Figure 3 for details). Looking at the $114^{\text {th }}$ Congress, we see the increasing polarization across the two camps and the leading roles of Republicans and the US Chamber of Commerce on the one hand and Democrats, environmental NGOs, and the Obama-led Environmental Protection Agency on the other hand. Proportionally, more subnational actors are located in the former camp as they share their rejection of the Clean Power Plan and the notion that the federal government should lead on climate policy with the Republican and business actors. As previously noted, more than half of the US states indicated their intention to challenge the Clean Power Plan when it was initially drafted, and 26 states filed suit against the Obama Administration over the Plan. ${ }^{3}$ Many of these states were represented in the hearings about climate change during the $114^{\text {th }}$ Session of Congress.

Overall, Figures 1-4, and especially the one-mode networks in Figure 4, show how a fragmented, polycentric system composed of multiple centers nested in two larger ideological camps

${ }^{3}$ For details, see https://www.eenews.net/interactive/clean power plan (Accessed 8 May 2019). 
increasingly polarized and homogenized into a system with two ideological centers and minimal belief overlap. The analysis demonstrates how actors from the subnational level were initially absent in this national-level policy arena and increasingly played a role in polarizing the two centers around the issue of the Clean Power Plan. These results can be characterized as an instance of a polycentric system that led to policy blockage, rather than innovation, through the multi-level activation of new actors, by means of polarization of the centers.

\section{Conclusion: Polycentricity in Climate Networks}

The results of this analysis clearly show how diverse actors worked together to promote their positions on the issue of climate change in the United States. As some governmental actors disengaged from climate discussions after the failure of the cap-and-trade bill, space opened up for other types of actors to participate in Congressional Hearings around the issue. Moreover, in the $113^{\text {th }}$ and $114^{\text {th }}$ Sessions, subnational actors became quite vocal about their views, many of whom were against states implementing the Clean Power Plan when it was proposed. In fact, before the Trump Administration took office (and subsequently repealed the Clean Power Plan), the Plan had been challenged in more than half of the 50 states in the United States and the Supreme Court had halted implementation of the Plan until cases in the lower courts were settled. ${ }^{4}$

In other words, these results clearly illustrate a polycentric approach to climate politics in the United States, with a participation of actors from multiple levels and actor types. Although the research on this subject has focused most of its attention on how polycentric governance can facilitate policies that encourage reductions in greenhouse gases (see particularly Cole 2015, Gillard et al. 2017; Jordan et al. 2018; Ostrom 2012), our case illustrates the ways that polycentricity can be

\footnotetext{
4 Details available at: http://www.eenews.net/interactive/clean power plan/fact sheets/legal (accessed 27 January 2018).
} 
used to block the implementation of such efforts. These findings add to the literature on polycentricity by illustrating how such collaboration by national and subnational actors at multiple levels and centers of the political sphere can work against, rather than in favor of, policy change that favors environmental outcomes. To restate, our results provide clear challenges to the predominant view in the literature that polycentric governance necessarily favors progressive outcomes.

Hence, this paper provides a first step towards understanding polycentricity that stagnates policy innovation. Future research should focus on fleshing out how a polycentric approach fits within both policy innovation and policy stagnation. In addition, future research should apply the polycentric approach to environmental issues beyond climate change, and even perhaps beyond environmental issues. We should note that in unpacking the black box of relationships between actors and centers in polycentric governance systems, our analysis is confined to ideological networks as one specific layer of relations and does not consider bargaining processes and coordination through policy forums as in the Ecology of Games literature. Although our approach provides an innovative view on polycentric governance, it should be complemented by these additional perspectives in future research to understand the innovative and stagnating mechanisms in polycentric systems more fully.

Methodologically, the present contribution employed mostly exploratory (discourse) network analysis. Future research should extend these descriptions and employ statistical network models to test hypotheses on network formation. Such analysis must be done in tandem with better theory development on how and why actors link to certain policy belief concepts - intrinsically or in response to the revealed positions of other actors -, and how and why political actors link to certain policy forums at any point in time. We anticipate that a multiplex view of these networks across multiple relations, node types, and levels holds both theoretical and empirical promise for developing a better understanding of how polycentricity works in practice. 
In terms of climate politics in the US, this paper provides evidence that policy actors outside the federal government have engaged in climate politics at multiple scales. Our analysis has documented how the Clean Power Plan was blocked in the US Congress and what role subnational actors took in this process. This paper provides a rare case in which policy blockage can be documented empirically. Polycentric governance played a key role in this process. Future research should dig more deeply into how subnational actors are addressing (or refrain from addressing) climate politics and other environmental politics at the federal or subnational levels. 
TABLE 1: PARTICIPATION IN CONGRESSIONAL HEARINGS BY ACTOR TYPE

\begin{tabular}{|c|c|c|c|c|c|c|}
\hline & \multirow{2}{*}{\multicolumn{2}{|c|}{$\begin{array}{c}\text { 112th Session } \\
\text { 2011-2013 } \\
\text { Democratic Senate, } \\
\text { Republican House }\end{array}$}} & \multirow{2}{*}{\multicolumn{2}{|c|}{$\begin{array}{c}\text { 113th Session } \\
\text { 2013-2015 } \\
\text { Democratic Senate, } \\
\text { Republican House }\end{array}$}} & \multirow{2}{*}{\multicolumn{2}{|c|}{$\begin{array}{c}114^{\text {th }} \text { Session } \\
2015-2017 \\
\text { Democratic Senate } \\
\text { Republican House }\end{array}$}} \\
\hline & & & & & & \\
\hline & $\mathbf{n}$ & $\%$ & $\mathbf{n}$ & $\%$ & $\mathbf{n}$ & $\%$ \\
\hline Business/ Business Associations & 18 & $21.2 \%$ & 35 & $17.9 \%$ & 233 & $28.8 \%$ \\
\hline Congressional-Democrats & 4 & $4.7 \%$ & 21 & $10.7 \%$ & 99 & $12.2 \%$ \\
\hline Congressional-Republicans & 3 & $3.5 \%$ & 25 & $12.8 \%$ & 120 & $14.8 \%$ \\
\hline Environmental Groups & 6 & $7.1 \%$ & 12 & $6.1 \%$ & 36 & $4.4 \%$ \\
\hline Non-Governmental Organizations & 7 & $8.2 \%$ & 15 & $7.7 \%$ & 86 & $10.6 \%$ \\
\hline Scientists/Academics & 25 & $29.4 \%$ & 29 & $14.8 \%$ & 57 & $7.0 \%$ \\
\hline $\begin{array}{l}\text { Subnational Governmental } \\
\text { Representatives }\end{array}$ & 6 & $7.1 \%$ & 23 & $11.7 \%$ & 72 & $8.9 \%$ \\
\hline US Administration Representatives & 16 & $18.8 \%$ & 34 & $17.3 \%$ & 93 & $11.5 \%$ \\
\hline Other & 0 & $0.0 \%$ & 2 & $1.0 \%$ & 14 & $1.7 \%$ \\
\hline TOTAL & 85 & & 196 & & 810 & \\
\hline
\end{tabular}


Figure 1: Ideological Climate Network in $112^{\text {th }}, 113^{\text {th }}$, and $114^{\text {th }}$ Sessions of Congress

112th Session

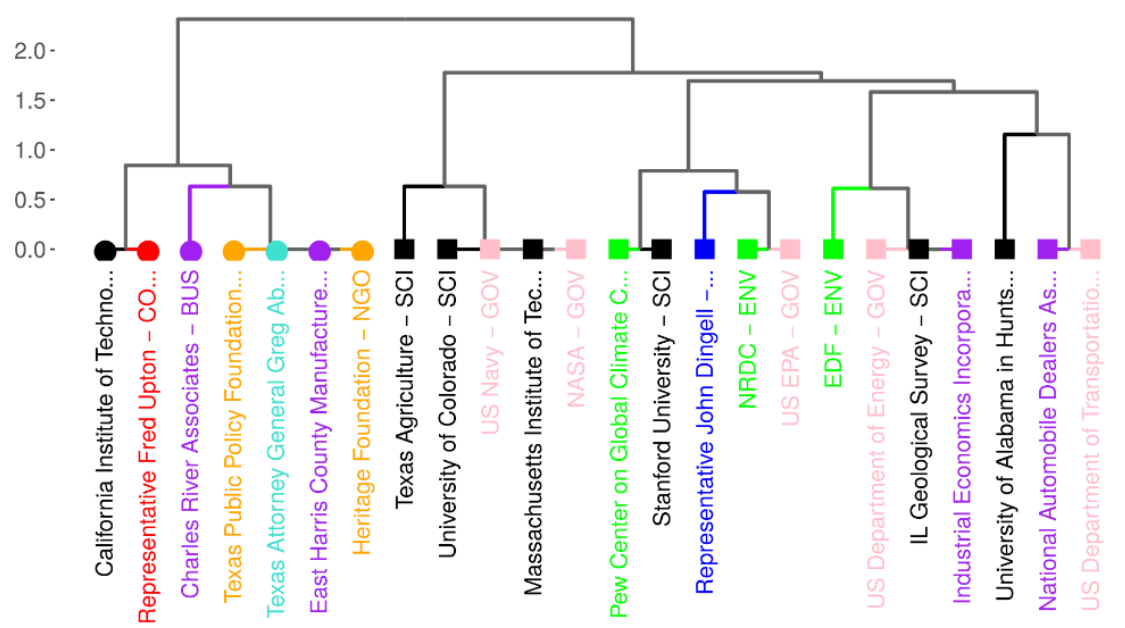

113th Session

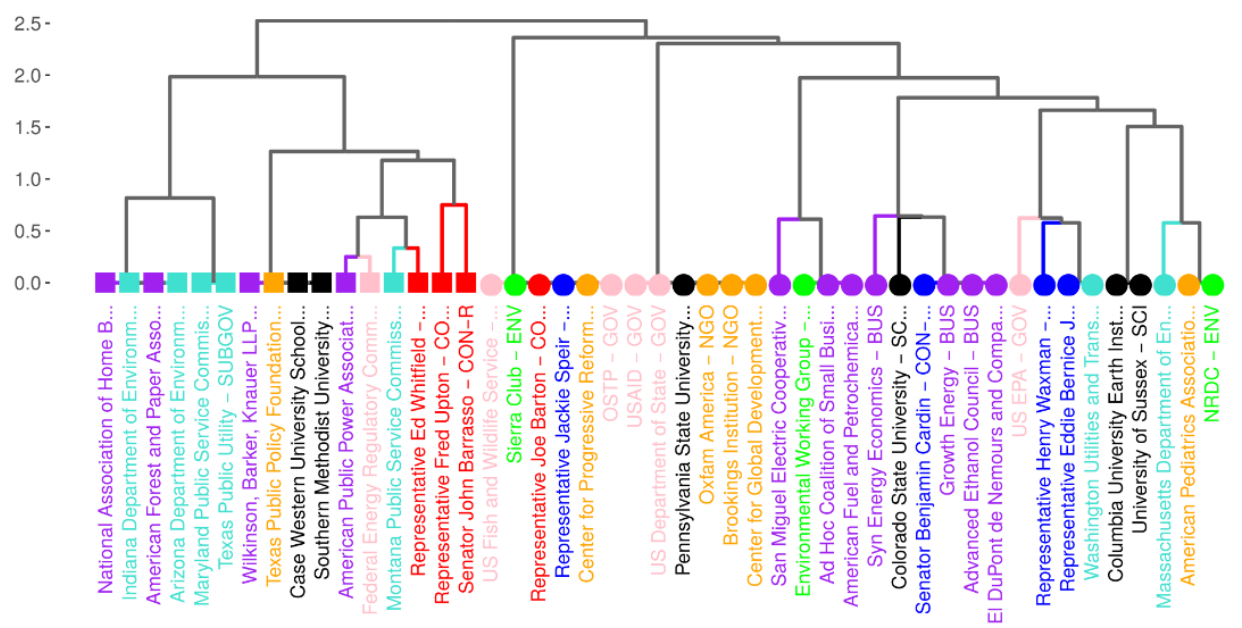

114th Session

4 .

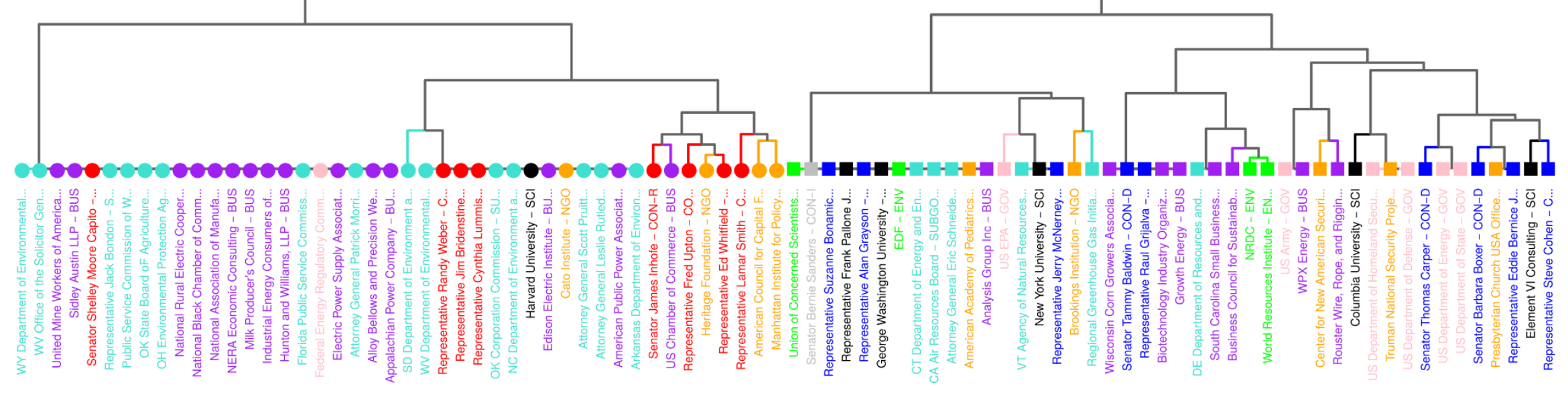


Figure 2: Actors' positive (green), negative (red), or ambiguous (blue) affiliation with policy beliefs in $112^{\text {th }}$ and $113^{\text {th }}$ Sessions of Congress

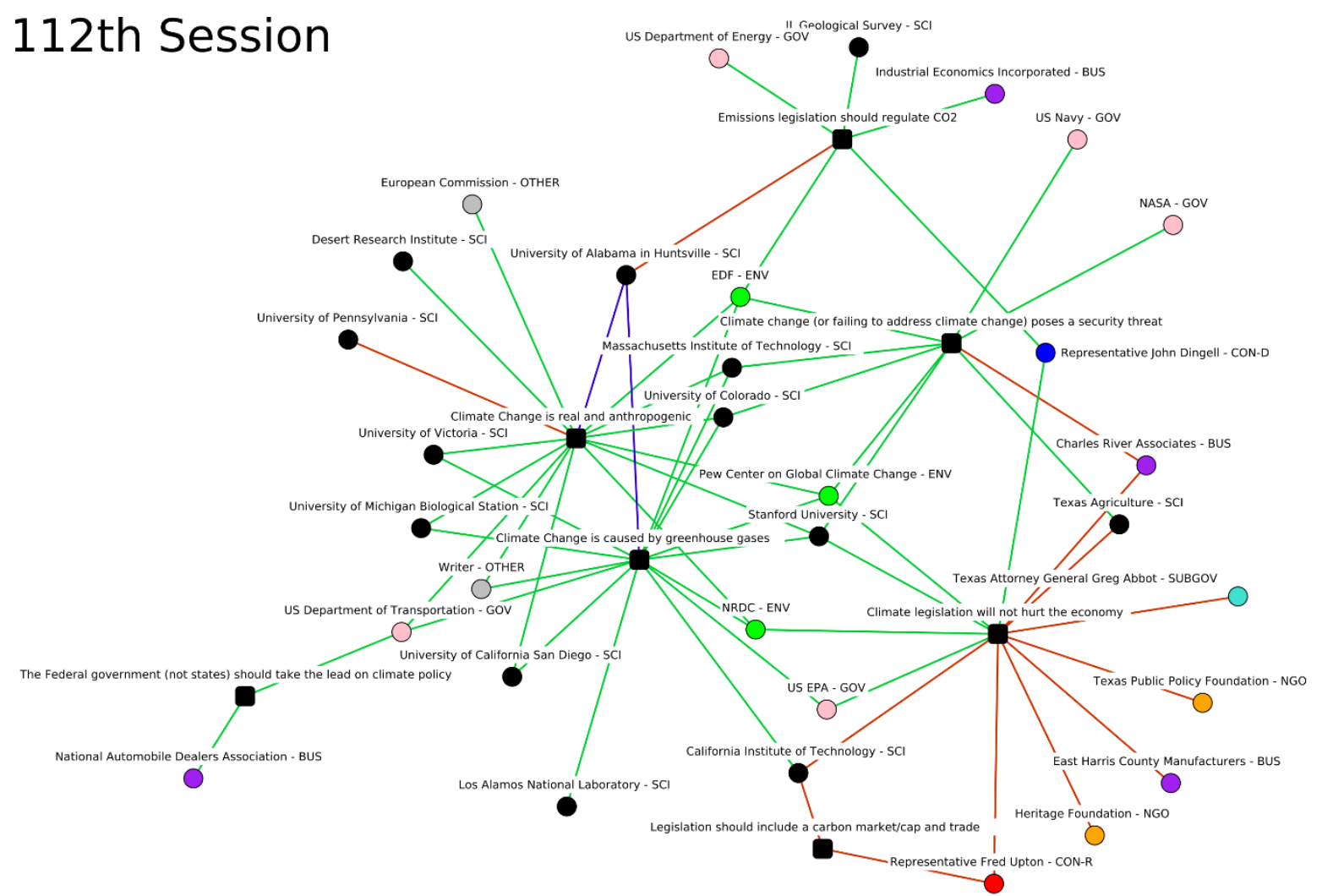

\section{3th Session}

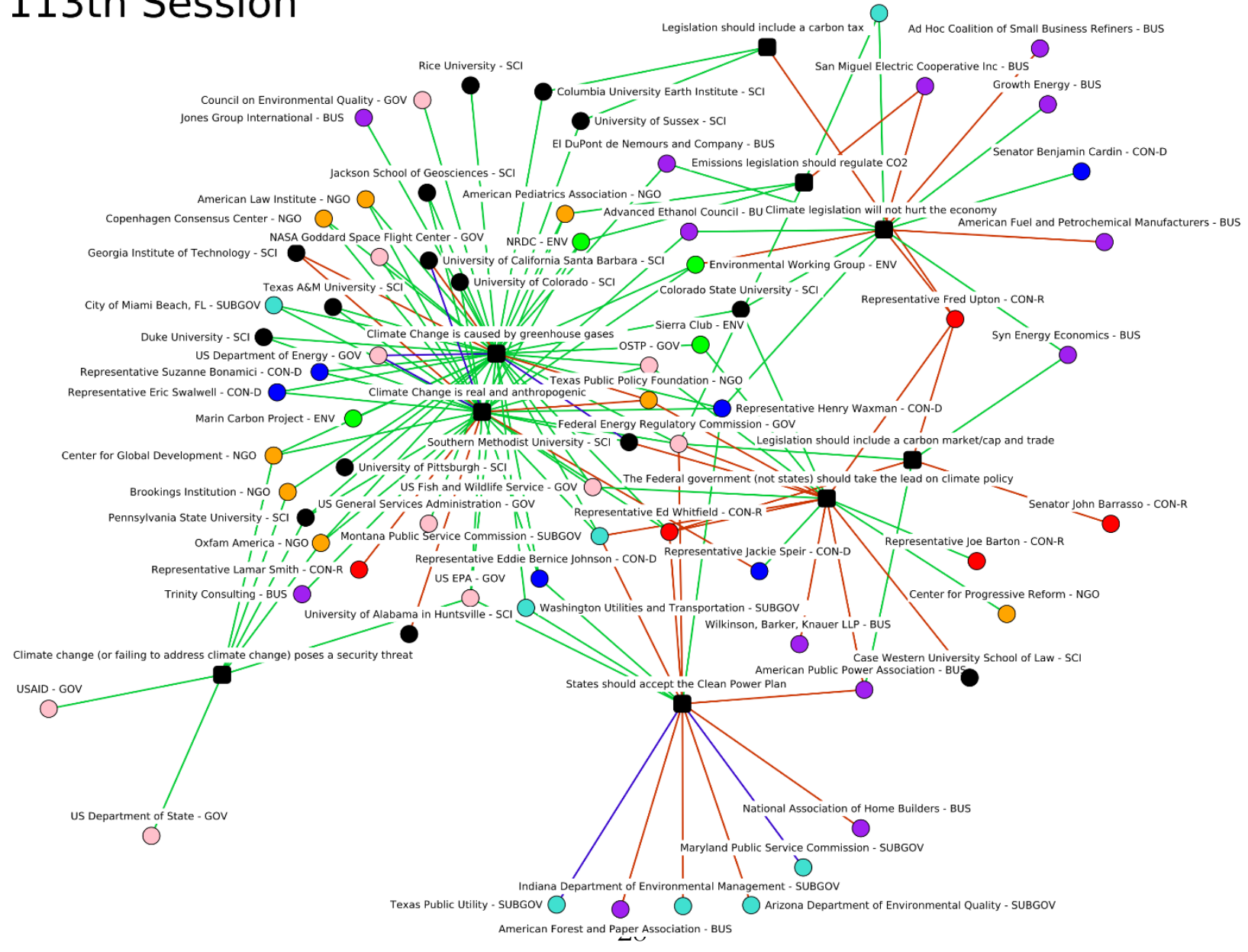


Figure 3: Same as Figure 2 with sub-governmental actors highlighted in $113^{\text {th }}$ and $114^{\text {th }}$

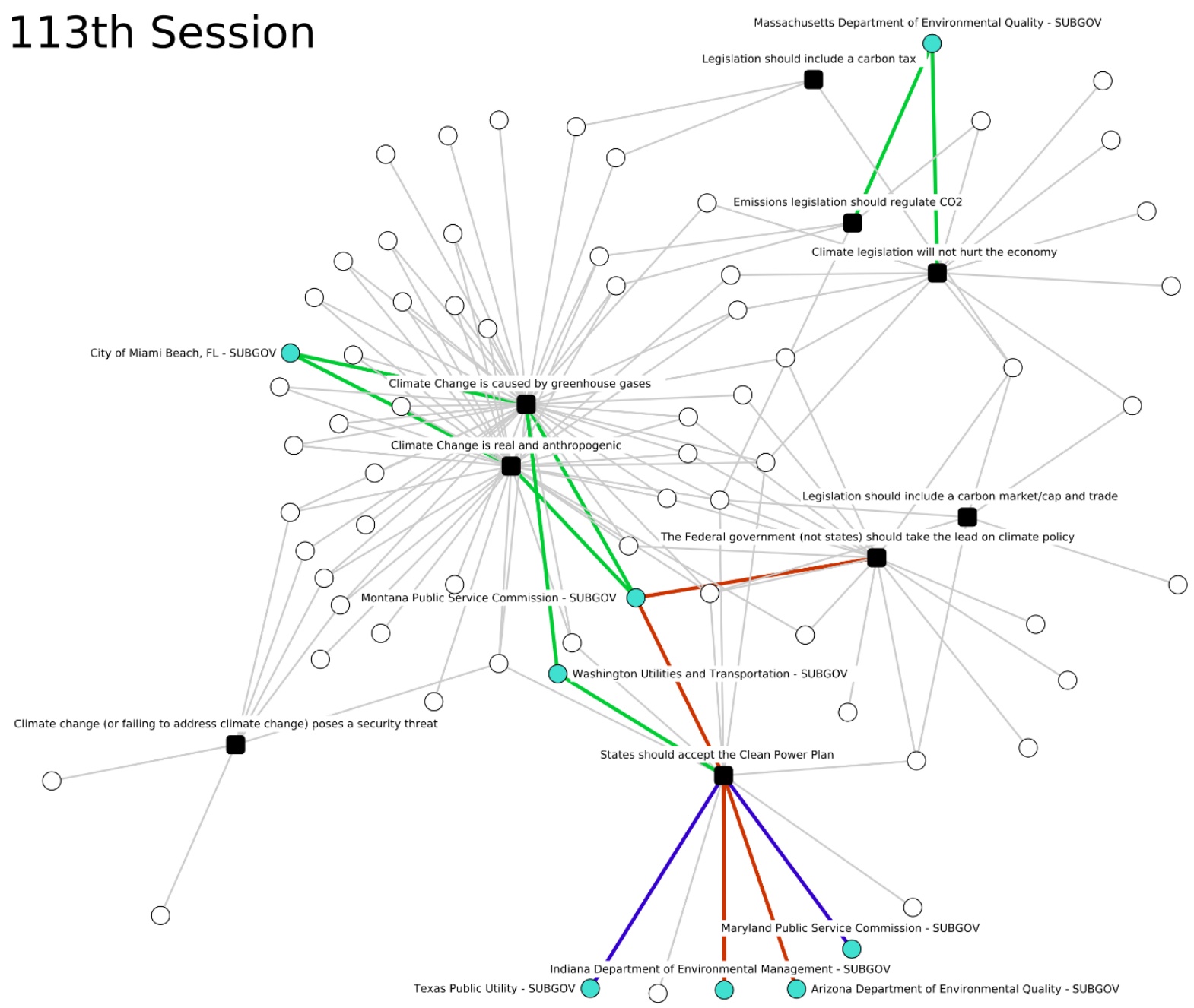

\section{4th Session}

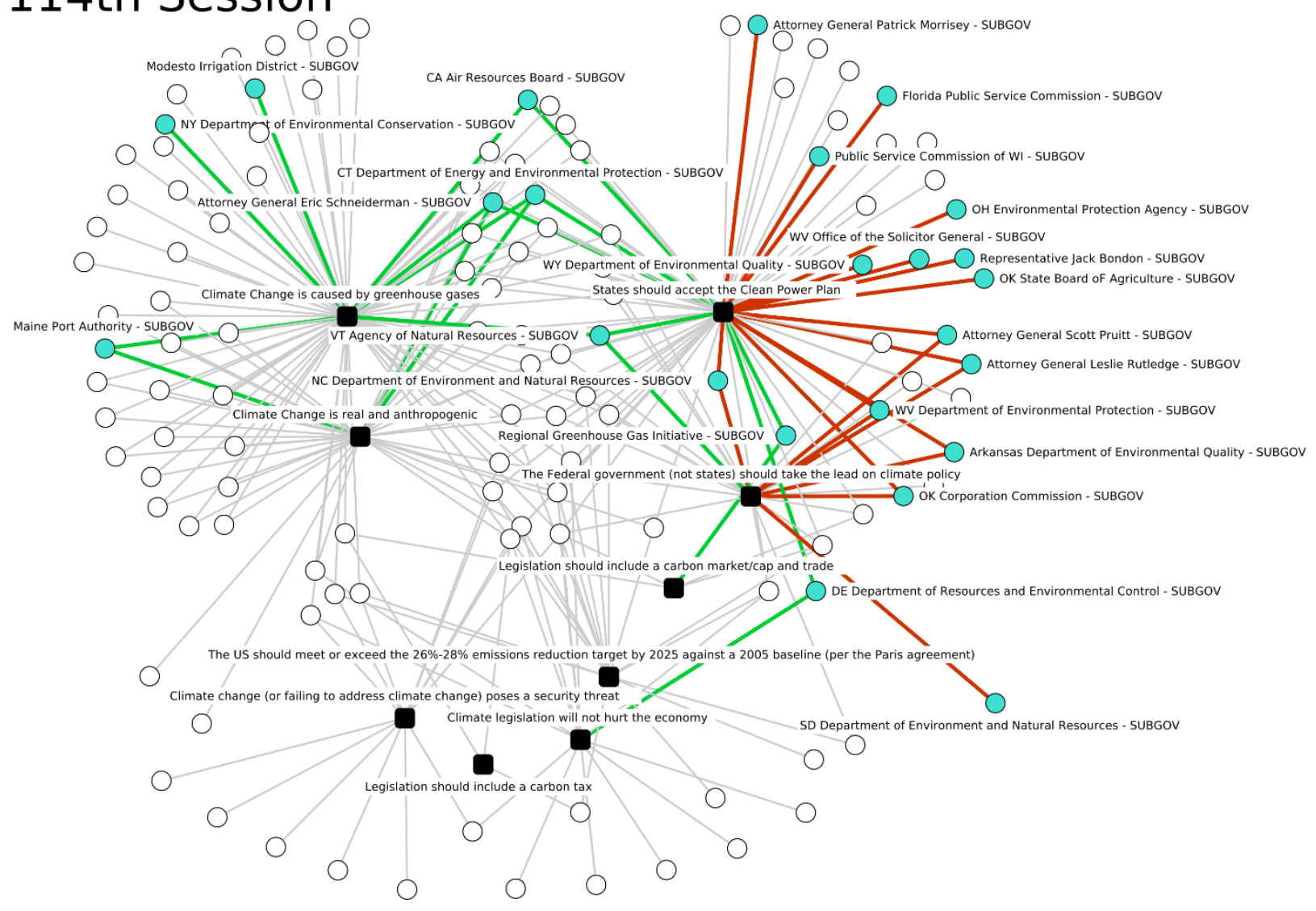


Figure 4: Actor congruence networks in $112^{\text {th }}, 113^{\text {th }}$, and $114^{\text {th }}$ Sessions of Congress, without science-related policy beliefs
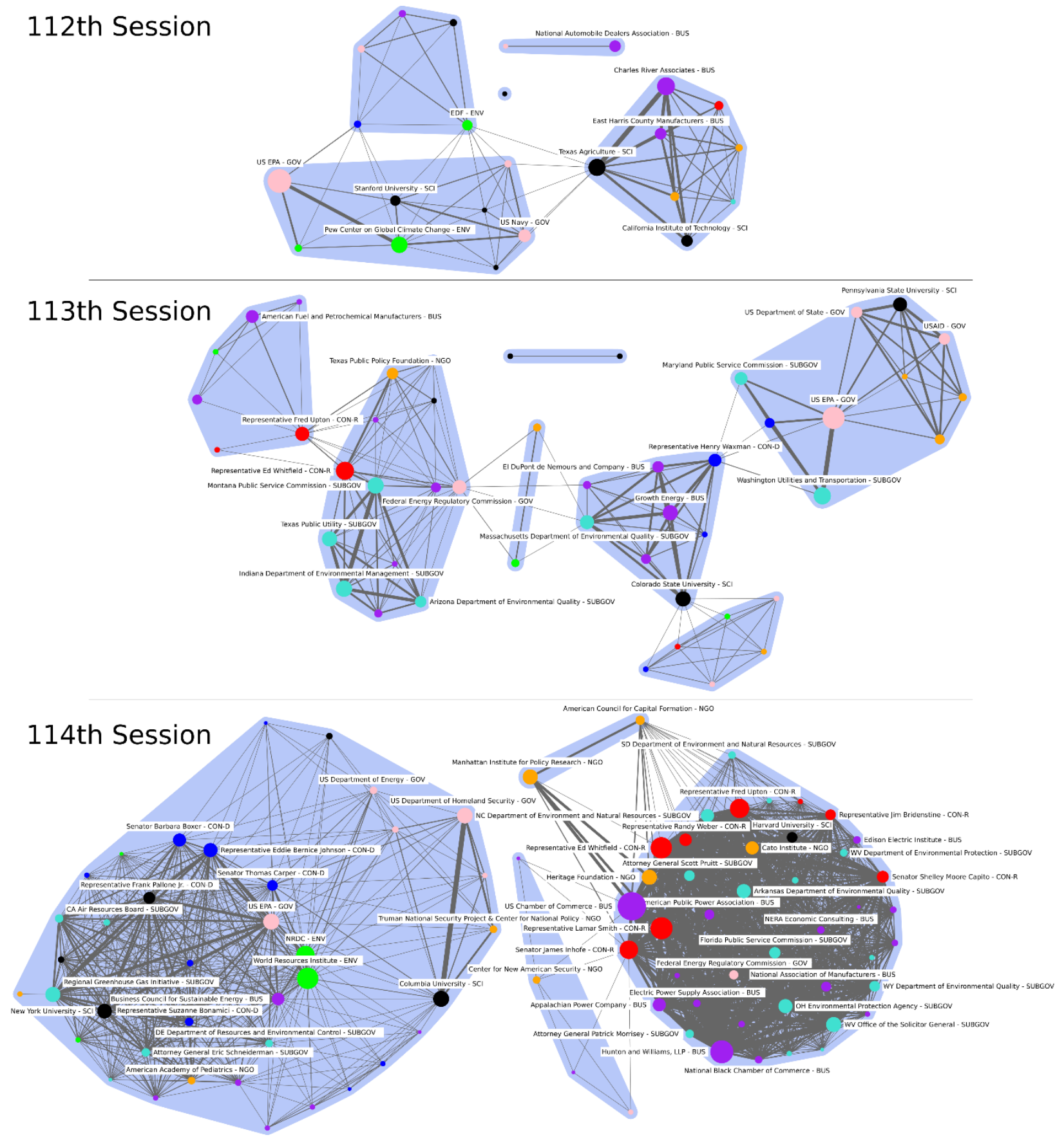


\section{References}

Berardo, Ramiro and Mark Lubell. 2019. "The Ecology of Games as a Theory of Polycentricity: Recent Advances and Future Challenges.” Policy Studies Journal 47(1):6-26.

Betsill, M. M. and H. Bulkeley. 2006. "Cities and the Multilevel Governance of Global Climate Change." Glob. Gov 12:141-159.

Blondel, Vincent D., Jean-Loup Guillaume, Renaud Lambiotte, and Etienne Lefebvre. 2008. “Fast Unfolding of Communities in Large Networks." Journal of Statistical Mechanics: Theory and Experiment 2008(10):P10008.

Bodin, Örjan. 2017. "Collaborative Environmental Governance: Achieving Collective Action in Social-Ecological Systems.” Science 357(6352):eaan1114.

Bulkeley, Harriet. 2005. "Reconfiguring Environmental Governance: Towards a Politics of Scales and Networks." Political Geography 24(8):875-902.

Burstein, Paul and C. Elizabeth Hirsh. 2007. "Interest Organizations, Information, and Policy Innovation in the US Congress." Pp. 174-199 in Sociological Forum. Vol. 22. Wiley Online Library.

Burt, Ronald S. 1995. Structural Holes: The Social Structure of Competition. 1 st Paperback Edition edition. Cambridge, Mass.: Harvard University Press.

Carlisle, Keith and Rebecca L. Gruby. 2017. "Polycentric Systems of Governance: A Theoretical Model for the Commons." Policy Studies Journal n/a-n/a.

Clifton, Brett M. 2004. "Romancing the GOP: Assessing the Strategies Used by the Christian Coalition to Influence the Republican Party." Party Politics 10(5):475-498.

Cole, Daniel H. 2011. "From Global to Polycentric Climate Governance.” Climate Law 2(3):395-413.

Cole, Daniel H. 2015. “Advantages of a Polycentric Approach to Climate Change Policy.” Nature Climate Change 5(2):114-18.

Congressional Research Service. 2015. House Committee Hearings: The "Minority Witness Rule."

DeGregorio, Christine. 1998. "Assets and Access: Linking Lobbyists and Lawmakers in Congress." The Interest Group Connection: Electioneering, Lobbying, and Policymaking in Washington. Chatham House Publishers, Chatham, p Viii 376.

Fischer, Manuel and Philip Leifeld. 2015. "Policy Forums: Why Do They Exist and What Are They Used For?” Policy Sciences 48(3):363-82.

Fisher, Dana R. 2013. "Understanding the Relationship between Subnational and National Climate Change Politics in the United States: Toward a Theory of Boomerang Federalism."

Environment and Planning C: Government and Policy 31(5):769-84. 
Fisher, Dana R., Philip Leifeld, and Yoko Iwaki. 2013. "Mapping the Ideological Networks of American Climate Politics." Climatic Change 116(3-4):523-545.

Fisher, Dana R., Joseph Waggle, and Philip Leifeld. 2013. "Where Does Political Polarization Come from? Locating Polarization within the US Climate Change Debate." American Behavioral Scientist 57(1):70-92.

García, María Mancilla and Örjan Bodin. 2019. "Participation in Multiple Decision Making Water Governance Forums in Brazil Enhances Actors' Perceived Level of Influence.” Policy Studies Journal 47(1):27-51.

Gillard, Ross, Andrew Gouldson, Jouni Paavola, and James Van Alstine. 2017. "Can National Policy Blockages Accelerate the Development of Polycentric Governance? Evidence from Climate Change Policy in the United Kingdom." Global Environmental Change 45:174-82.

Gormley Jr, William T. 1998. “Witnesses for the Revolution.” American Politics Quarterly 26(2):174195.

Hamilton, Matthew and Mark Lubell. 2018. "Collaborative Governance of Climate Change Adaptation Across Spatial and Institutional Scales.” Policy Studies Journal 46(2):222-47.

Harris, BA. 2016. "What the Supreme Court's Stay of the Clean Power Plan Means for the EPA's Greenhouse Gas Regulation Moving Forward.” UCLA Journal of Environmental Law \& Policy. Retrieved August 7, 2018 (http://vjel.vermontlaw.edu/what-the-supreme-courts-stay-of-theclean-power-plan-means-for-the-epas-greenhouse-gas-regulation-moving-forward/).

Harvard Law Review. 2016. “The Clean Power Plan.” Harvard Law Review 129(4):1152-59.

Heitshusen, Valerie. 2017. Senate Committee Hearings: Arranging Witnesses. Congressional Review Service Report for Congress.

Jain, Anil K. and Richard C. Dubes. 1988. Algorithms for Clustering Data. Upper Saddle River, NJ, USA: Prentice-Hall, Inc.

Jasny, Lorien, Joseph Waggle, and Dana R. Fisher. 2015. "An Empirical Examination of Echo Chambers in US Climate Policy Networks.” Nature Climate Change 5(8):782-86.

Jones, Bradford S. 1991. "State Responses to Global Climate Change.” Policy Studies Journal 19(2):7382.

Jordan, Andrew, Dave Huitema, Harro van Asselt, and Johanna Forster. 2018. Governing Climate Change: Polycentricity in Action? Cambridge, UK: Cambridge University Press.

Jordan, Andrew J., Dave Huitema, Mikael Hildén, Harro van Asselt, Tim J. Rayner, Jonas J. Schoenefeld, Jale Tosun, Johanna Forster, and Elin L. Boasson. 2015. "Emergence of Polycentric Climate Governance and Its Future Prospects." Nature Climate Change 5(11):97782. 
Koontz, Tomas M., T. A. Steelman, J. Carmin, K. S. Korfmacher, C. Moseley, and C. W. Thomas. 2004. Collaborative Environmental Management: What Roles for Government? Washington, DC: Resources for the Future.

Krane, Dale. 2007. "The Middle Tier in American Federalism: State Government Policy Activism during the Bush Presidency." Publius: The Journal of Federalism 37(3):453-477.

Laumann, Edward O. and David Knoke. 1987. The Organizational State: Social Choice in National Policy Domains. Univ of Wisconsin Press.

Leifeld, Philip. 2016. Policy Debates as Dynamic Networks: German Pension Politics and Privatization Discourse. Frankfurt New York NY: Campus Verlag.

Leifeld, Philip. 2017. "Discourse Network Analysis: Policy Debates as Dynamic Networks." Pp. 301-25 in The Oxford Handbook of Political Networks, edited by J. N. Victor, A. H. Montgomery, and M. N. Lubbell. Oxford University Press.

Leifeld, Philip. 2019. RDNA. Discourse Network. Analysis in R. R Package Version 2.1.18.

Leifeld, Philip, Johannes Gruber, and Felix Rolf Bossner. 2018. Discourse Network Analyzer Manual.

Leifeld, Philip and Sebastian Haunss. 2012. "Political Discourse Networks and the Conflict over Software Patents in Europe." European Journal of Political Research 51(3):382-409.

Liu, Xinsheng, Eric Lindquist, and Arnold Vedlitz. 2011. "Explaining Media and Congressional Attention to Global Climate Change, 1969-2005: An Empirical Test of Agenda-Setting Theory." Political Research Quarterly 64(2):405-19.

Lubell, Mark, Adam Douglas Henry, and Mike McCoy. 2010. "Collaborative Institutions in an Ecology of Games.” American Journal of Political Science 54(2):287-300.

McCright, Aaron M. and Riley E. Dunlap. 2003. "Defeating Kyoto: The Conservative Movement's Impact on US Climate Change Policy.” Social Problems 50(3):348-373.

McGee, Zachary A. and Bryan D. Jones. 2019. "Reconceptualizing the Policy Subsystem: Integration with Complexity Theory and Social Network Analysis.” Policy Studies Journal 47(S1):S138-58.

Morrison, Tiffany H. 2017. "Evolving Polycentric Governance of the Great Barrier Reef." Proceedings of the National Academy of Sciences 114(15):E3013-21.

Newman, M. E. J. 2006. "Modularity and Community Structure in Networks." Proceedings of the National Academy of Sciences of the United States of America 103(23):8577-82.

Obama, Barack. 2015. "Remarks by the President in Announcing the Clean Power Plan." The White House of President Barack. Obama. Retrieved (https:/ /obamawhitehouse.archives.gov/the-pressoffice/2015/08/03/remarks-president-announcing-clean-power-plan).

Oberthür, Sebastian. 2016. "Reflections on Global Climate Politics Post Paris." The International Spectator 51(4):80-94. 
Ostrom, Elinor. 2012. "Nested Externalities and Polycentric Institutions: Must We Wait for Global Solutions to Climate Change before Taking Actions at Other Scales?" Economic Theory 49(2):353-69.

Ostrom, Elinor. 2014. "A Polycentric Approach For Coping With Climate Change." Annals of Economics and Finance 15(1):71-108.

Park, Hyung Sam, Xinsheng Liu, and Arnold Vedlitz. 2010. "Framing Climate Policy Debates: Science, Network, and US Congress, 1976-2007.”

Rabe, Barry. 2007. "Environmental Policy and the Bush Era: The Collision Between the Administrative Presidency and State Experimentation." Publius: The Journal of Federalism 37(3):413-31.

Rabe, Barry. 2013. "Racing to the Top, the Bottom, or the Middle of the Pack? The Evolving State Government Role in Environmental Protection." Pp. 30-53 in Environmental policy: New directions for the 21st Century, edited by N. Vig and M. Craft. Washington, DC: CQ Press.

Rabe, Barry and Christopher Borick. 2013. "Conventional Politics for Unconventional Drilling? Lessons from Pennsylvania’s Early Move into Fracking Policy Development.” Review of Policy Research 30(3):321-40.

Sabatier, Paul A. and Christopher M. Weible. 2007. "The Advocacy Coalition Framework" edited by P. A. Sabatier. Theories of the Policy Process 2:189-220.

Scott, Tyler A. and Robert A. Greer. 2019. "Polycentricity and the Hollow State: Exploring Shared Personnel as a Source of Connectivity in Fragmented Urban Systems.” Policy Studies Journal 47(1):52-76.

Spreng, Connor P., Benjamin K. Sovacool, and Daniel Spreng. 2016. "All Hands on Deck: Polycentric Governance for Climate Change Insurance.” Climatic Change 139(2):129-40.

The New York Times. 2017. "What Is the Clean Power Plan, and How Can Trump Repeal It?" The New York Times, October 10.

Ward, Joe H. Ward. 1963. "Hierarchical Grouping to Optimize an Objective Function." Journal of the American Statistical Association 58(301):236-44. 